carbon in series four of the periodic table, namely, titanium, zirconium, cerium, and thorium. Indeed, "carbonaceous matter" is itself recorded by Prof. Rosenbusch ("Rock-making Minerals," p. 197) as giving rise to pleochroic halos in andalusite. Of course, this might imply nothing more than that chemical similarity leads to similar impurities (e.g. thorium), to which the radioactivity may be due. It is not easy to see how such an explanation would fit the case of carbon, but otherwise it would readily account for the fact that halos are not always seen round the minerals mentioned above, and that they may occur round some crystals and yet not round others in the same rock. They are most common, indeed practically constant, round zircon and orthite, but are confined to a few occurrences of the abundant minerals sphene, apatite, and epidote.

Another point which seems to deserve emphasis is the fact that, from a geological point of view, the radioactivity of thorium must surely be a far more potent factor than that of uranium and its derivatives. For there is no mineral which occurs in ordinary rocks which appears to contain uranium in quantities appreciable by chemical methods, whereas, as will be inferred from what has been already said, thorium is of extremely wide distribution.

Bulawayo, Rhodesia, October 18. F. P. Mennell.

\section{Magnetic Storms.}

IN his letter (Nature, November Ir) Dr. Simpson raises an argument as to the absence of corresponding changes in the electrical potential gradient during magnetic storms which, if admitted, would, I imagine, prove a serious difficulty in the "electron stream" theory of magnetic disturbances. On the assumption that the arriving stream induces an opposite charge which resides at the earth's surface, we can agree with Dr. Simpson's calculation, except that, since there are two current sheets of opposite sign, the potential gradient ought to be half what he finds.

It seems to me most unlikely that the induced charge resides at the earth's surface. The atmosphere is slightly conducting, and it is throughout it that the induced charge distributes itself. It is well known that a very slightly conducting shell will with great rapidity act as a perfect electrostatic screen, but, on the contrary, fails to screen magnetic effects. In his paper (Phil. Trans., A, 1908) on terrestrial magnetism, Dr. Schuster points out that the normal conductivity of air at the earth's surface is about $\mathrm{ro}^{-24}$, while at a height such that the pressure is I dyne per sq. $\mathrm{cm}$. the conductivity would be about Io-18 $^{-18}$. For such a conductivity the time constant of decay would be about $10^{-4}$ of a second, or, in other words, practically complete electrostatic screening would be established in about one-thousandth part of a second, and correspondingly the slight initial magnetic screening would then cease. We have thus a simple explanation of the absence of direct electrostatic effects at the surface of the earth due to "electron streams" several hundred kilometres above the earth. The earth currents which do accompany magnetic storms are thus referred, not to electrostatic induction, but to change of magnetic induction at the earth's surface.

Eskdalemuir Magnetic Observatory, November I2.

\section{The Photometric Measurement of the Obliquity Factor} of Diffraction.

IN vol. Ixxviii. of NaruRe (May 21, I908, p. 55) was published a note on "Secondary Waves of Light," in which I described the diffraction effects produced by an obliquely held rectangular aperture or reflecting surface, and pointed out that the observed distribution of illumination in the pattern was not in accordance with that deduced in the ordinary way. I indicated an explanation of the discrepancy, that it was due to the variation of the obliquity factor of diffraction within the limits of the pattern.

The interest of the observations lay in the fact that such an effect had never been noticed before, and that the observations enabled us actually to trace the variation of the amplitude of vibration from point to point on
Huygens's secondary waves. A full description of the effect and a mathematical investigation were published in the Philosophical Magazine for January.

The effect observed was that the intensities of illumination in corresponding bands on opposite sides of the central band in the unsymmetrical pattern were unequal. A photometric investigation of this difference in illumination has been carried out. The method was to use revolving sectors to reduce the illumination in one of the two bands to be compared, so as to make them both of equal brightness. The following table illustrates the comparisons made :-

$$
\begin{aligned}
& \text { Ne. of Ratio of illumina- Ratio of illumina- Ratio of illumira- } \\
& \text { expt. tion according to tion actually tion calculated } \\
& \text { I ... I I OO } \quad \ldots \quad \text { determined from obliquity } \\
& \begin{array}{lllllll}
\mathbf{1} & \ldots & 1.00 & \cdots & \mathrm{I} \cdot 66 & \ldots & \mathrm{I} \cdot 6 \mathrm{I} \\
2 & \ldots & 1.00 & \cdots & \mathrm{I} \cdot 8 \mathrm{I} & \cdots & \mathrm{I} \cdot 98
\end{array}
\end{aligned}
$$

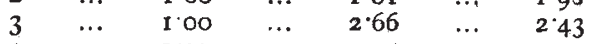

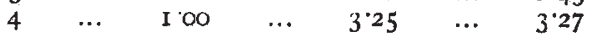

The obliquity law demonstrated by these measurements is that, in the hemispherical wavelets emitted by each element of a transmitting aperture or reflecting surface upon which waves are incident at any angle, the amplitude of the light vector is, at any point in the plane of incidence, proportional to the cosine of the angle made by the line joining that point and the element, with the normal to the plane of the element.

Post-Box 59, Rangoon.

\section{Mendelian Heredity: A Correction.}

I SHOULD be glad of an opportunity of correcting the following errors in my book "Mendel's Principles of Heredity ":-

On p. 35, Davenport's result regarding rumplessness in fowls is accidentally inverted. The character, according to him, is recessive, not dominant as stated by me. I have to thank Prof. Arnold Lang for this correction.

The other, and more serious, error is in the description of Fig. 34 of the second impression of the book (p. 23I). In giving a tentative scheme for the descent of colourblindness, I there stated that a male homozygous for colour-blindness could be produced by the mating of two colour-blind parents; but if the scheme is right, it evidently follows that such a male cannot be formed even from that mating.

November 12.

W. Bateson.

\section{The Functions of the Martian Canals.}

Wiтн reference to the recent paper by Dr. Pocklington before the Royal Society, on the functions of the Martian canals, a notice of which appeared in NATURE of November I I (p. 58 ), I should like to suggest that these canals may perhaps be used for power-storage purposes. In Mars, possibly, there are seasons of winds or monsoons during which the upper reaches of the canals would be pumped full by innumerable windmills, and the power thus stored utilised during calm seasons, and transmitted electrically for lighting, heating, and general power purposes. For a population which had exhausted all its mineral fuel, which possessed no extensive ocean, and whose soil and climate were unsuitable for the growth of fuel, this would indeed appear to be the only means of obtaining heat and power. The same canals could serve the triple purposes of communication, power, and irrigation. H. F. Hunt.

7 Officers' Row, Pembroke Dock, Wales, November 13 .

\section{GRAVITY SURVEY.'}

THE two publications described below afford a remarkable example of the value of an International Bureau worked in the right spirit and used in the right way. The sumptuous institute upon the Telegraphenberg at Potsdam is the home of the 1 " "Survev of India : Professional Paper, No. 1o. The Pendulum Operaan appendix by A. Strahan, F.R.S. Pp. ix + rg6. (Dehra Dun, roo8.) "Deutsche Südpolar Expedition, I90r-3." Band i., Geographie ; Heft iii., Die Schwerkraftsbestimmungen der Deutschen Südpolar Expedițion. By E. von Drygalski und L. Haasemann. Pp. 285-363. (Berlin : Georg Reimer, rgog.) Price 12.80 marks.

NO. 209O, VOL. 82] 